\title{
Expression profile of matricellular proteins in hypertrophied right ventricle of monocrotaline-induced pulmonary hypertensive rats
}

\author{
Keisuke IMOTO'1), Muneyoshi OKADA ${ }^{1) *}$ and Hideyuki YAMAWAKI') \\ 1)Laboratory of Veterinary Pharmacology, School of Veterinary Medicine, Kitasato University, Higashi 23 bancho \\ 35-1, Towada-shi, Aomori 034-8628, Japan
}

\begin{abstract}
Matricellular proteins, a non-structural extracellular matrix (ECM) component, bind to and modulate various molecules including growth factor, cytokine, protease, other ECM components and cell membrane receptors. While most matricellular proteins are hardly expressed in normal adult tissue, they are re-expressed in heart tissue during cardiac diseases. The present study aimed to clarify the mRNA expression profile of matricellular proteins [secreted protein acidic and rich in cysteine: SPARC, hevin, thrombospondin (TSP)- $1,-2$ and -4 , CCN1 and 5, tenascin (Tn) C and N, periostin and osteopontin (OPN)] in hypertrophied right ventricle (RV) of monocrotaline (MCT)-induced pulmonary hypertensive rats. Male Wistar rats were intraperitoneally treated with MCT or saline. Two or three weeks after MCT treatment, echocardiography was performed, and mRNA expression of matricellular proteins was measured by real-time polymerase chain reaction. MCT ( 2 weeks) induced pulmonary hypertension, RV dysfunction and hypertrophy, which were all worsened 3 weeks after MCT treatment. Expression of mRNA for SPARC, hevin, TnC, TSP-1, -2 and -4, CCN1 and 5, periostin and OPN but not TnN was significantly upregulated in RV of MCT ( 2 weeks)-treated rats. Expression of mRNA for TSP-4, CCN1 and 5 and periostin was continuously increased in RV of MCT ( 3 weeks)-treated rats. The present study for the first time revealed the mRNA expression profile for matricellular proteins in RV of MCT-treated rats for 2 or 3 weeks, which will be helpful to clarify the relationship for matricellular proteins and pathogenesis of MCT-induced RV hypertrophy.
\end{abstract}

J. Vet. Med. Sci.

79(6): 1096-1102, 2017 doi: 10.1292/jvms.17-0053

Received: 2 February 2017 Accepted: 26 April 2017 Published online in J-STAGE:

11 May 2017
KEY WORDS: extracellular matrix, matricellular proteins, monocrotaline, pulmonary hypertension, right ventricular hypertrophy

Cardiac hypertrophy is a compensatory response to a sustained mechanical stress caused by underlying diseases, such as systemic hypertension, aortic stenosis and pulmonary hypertension [7, 8, 21]. Persistent pressure overload promotes cardiac remodeling including cardiac fibrosis as well as dysfunction, which leads to heart failure [21, 31]. In particular, right ventricle (RV) has poorer tolerance against the persistent pressure overload and is easy to change from adaptive to maladaptive hypertrophic state with higher mortality rate [20, 22]. Generally, the renin-angiotensin-aldosterone system, $\beta$-adrenergic receptor and calcium channel are involved in the development of heart failure and are the main targets for treatment of systemic hypertensive heart diseases including left ventricular hypertrophy $[17,21]$. However, an optimal pharmaco-therapeutic target against RV hypertrophy and failure induced by pulmonary artery hypertension has not yet been determined.

Remodeling of extracellular matrix (ECM) by activated cardiac fibroblasts and disruption of cardiomyocyte-ECM interactions are important determinants of systolic disorder through the disturbance of cooperative myocardial contraction [2]. Cardiac ECM is composed of numerous members including structural proteins, such as collagen, proteoglycan and non-structural proteins [6]. Matricellular proteins, a family of non-structural ECM components, bind to various molecules including growth factor, cytokine, protease, other ECM components and cell membrane receptors [6]. Matricellular proteins are rarely expressed in normal adult heart tissue. [6]. In various heart disease models including pressure-overloaded left ventricular hypertrophy or myocardial infarction, matricellular proteins [secreted protein acidic and rich in cysteine (SPARC) family, thrombospondin (TSP) family, CCN family, tenascin $(\mathrm{Tn})$ family, periostin and osteopontin $(\mathrm{OPN})$ ] are upregulated and involved in the progression of pathological condition

*Correspondence to: Okada, M., Laboratory of Veterinary Pharmacology, School of Veterinary Medicine, Kitasato University, Higashi 23 bancho 35-1, Towada-shi, Aomori 034-8628, Japan. e-mail: mokada@vmas.kitasato-u.ac.jp

(02017 The Japanese Society of Veterinary Science

This is an open-access article distributed under the terms of the Creative Commons Attribution Non-Commercial No Derivatives (by-ncnd) License. (CC-BY-NC-ND 4.0: https://creativecommons.org/licenses/by-nc-nd/4.0/) 
Table 1. Primer sequences used for real-time polymerase chain reaction

\begin{tabular}{|c|c|c|}
\hline Gene & Primer sequences & Accession number \\
\hline \multirow[t]{2}{*}{ SPARC $^{\text {a) }}$} & Forward: 5'-GACAGGGTTACCTGTGGGTG-3' & NM_012656.1 \\
\hline & Reverse: 5'-AATGATGGTTCTGGCAGGGG-3' & \\
\hline \multirow[t]{2}{*}{ Hevin } & Forward: 5'-AACACGGAAAACCCCACTGT-3' & NM_012946.1 \\
\hline & Reverse: 5'-CCACAAGCTTGGTCGAGGAT-3' & \\
\hline \multirow[t]{2}{*}{ TSP-1 $1^{b)}$} & Forward: 5'-TCGGGGCAGGAAGACTATGA-3' & NM_001013062.1 \\
\hline & Reverse: 5'-ACTGGGCAGGGTTGTAATGG-3' & \\
\hline \multirow[t]{2}{*}{ TSP-2 } & Forward: 5'-TCGCCGTAGGTTTCGATGAG-3' & NM_001169138.1 \\
\hline & Reverse: 5'-TAGTCATCGTCCCGGTCAGT-3' & \\
\hline \multirow[t]{2}{*}{ TSP-4 } & Forward: 5'- GCTACATCAGGGTGCGGTTT-3' & NM_017133.1 \\
\hline & Reverse: 5'- ACAGCGGTACTTGAGGTTGG-3' & \\
\hline \multirow[t]{2}{*}{ CCN1 } & Forward: 5'-GGATCTGTGAAGTGCGTCCT-3' & NM_031327.2 \\
\hline & Reverse: 5'-ATCGGACTGGTTCTGGGGAT-3' & \\
\hline \multirow[t]{2}{*}{ CCN5 } & Forward: 5'-CAAGGGACACGGTGACATGA-3' & NM_031590.1 \\
\hline & Reverse: 5'-GGGCACACACCATTGAGAGA-3' & \\
\hline \multirow[t]{2}{*}{$\mathrm{TnC}^{\mathrm{c})}$} & Forward: 5'-CGCAAAAATGGACGTGAGGA-3' & NM_053861.1 \\
\hline & Reverse: 5'-AGGTTATCCAGTCCAAGCCAG-3' & \\
\hline \multirow[t]{2}{*}{$\mathrm{TnN}$} & Forward: 5'-CACAGCAGGGGATGCTCTTA-3' & NM_001107189.2 \\
\hline & Reverse: 5'-CTTATACCACCAGCCGCCAT-3' & \\
\hline \multirow[t]{2}{*}{ Periostin } & Forward: 5'-TGCAAAAAGACACACCTGCAAA-3' & NM_001108550.1 \\
\hline & Reverse: 5'-GGCCTTCTCTTGATCGCCTT-3' & \\
\hline \multirow[t]{2}{*}{$\mathrm{OPN}^{\mathrm{d})}$} & Forward: 5'-CCAGCCAAGGACCAACTACA-3' & NM_012881.2 \\
\hline & Reverse: 5'-AGTGTTTGCTGTAATGCGCC-3' & \\
\hline \multirow[t]{2}{*}{$\mathrm{GAPDH}^{\mathrm{e})}$} & Forward: 5'-GAGAATGGGAAGCTGGTCAT-3' & NM_017008.4 \\
\hline & Reverse: 5'-GAAGACGCCAGTAGACTCCA-3' & \\
\hline
\end{tabular}

$[9,16,19,24,28-30,33]$. Kögler et al. reported that enhanced biomechanical load is necessary to induce the changes in gene expression associated with the hypertrophic phenotype in the pressure-overloaded RV [14]. While mRNA and protein expression of $\mathrm{TnC}$ was reported to be upregulated in hypertrophied $\mathrm{RV}$ from monocrotaline (MCT)-treated pulmonary hypertensive rats [9], the expression level of other matricellular proteins has not yet been clarified. Thus, the present study aimed to clarify the mRNA expression profile of matricellular proteins in hypertrophied RV from MCT-treated pulmonary hypertensive rats.

\section{MATERIALS AND METHODS}

\section{Animals}

An animal study was approved by the President of Kitasato University through the judgment of the Institutional Animal Care and Use Committee of Kitasato University (Approval no. 16-043). All animal care and experiments were conducted in accordance with the institutional guidelines of Kitasato University and National Institutes of Health Guide for the Care and Use of Laboratory Animals. Four to eight-week-old male Wistar rats (Clea Japan, Inc., Tokyo, Japan) were maintained with a standard laboratory diet and tap water and exposed to a $12 \mathrm{hr} / 12 \mathrm{hr}$ light-dark cycle at $23 \pm 2^{\circ} \mathrm{C}$ and $50-60 \%$ humidity.

\section{MCT-induced rat right heart failure model}

MCT (Wako, Osaka, Japan) dissolved in $1 \mathrm{~N} \mathrm{HCl}$ was neutralized to $\mathrm{pH} 7-8$ with $1 \mathrm{~N} \mathrm{NaOH}$ and diluted to $24 \mathrm{mg} / \mathrm{ml}$ with saline. Four-week-old male Wistar rats received a single MCT $(60 \mathrm{mg} / \mathrm{kg})$ injection via intraperitoneal cavity as described previously [17]. Control rats received an equal volume of saline injection.

\section{Real-time polymerase chain reaction (PCR)}

$\mathrm{RV}$ was removed under pentobarbital sodium anesthesia (100 mg/kg, i.p.). Total RNA of RV was isolated using an RNA isolation kit (TRI Reagent, Molecular Research Center, Montgomery, OH, U.S.A.). One $\mu \mathrm{g}$ of the RNA was reverse-transcribed using ReverTra Ace qPCR master mix (TOYOBO, Osaka, Japan) according to the manufacturer's instruction. Real-time PCR was performed using THUNDERBIRD SYBR qPCR Mix (TOYOBO) in 96-well PikoReal Real-time PCR system (ThermoFisher Scientific, Waltham, MA, U.S.A.). The primer sequence and the accession number of each primer used for real-time PCR are shown in Table 1. All the primers were designed from the exon-exon junction for each mRNA. The relative matricellular protein mRNA level to GAPDH mRNA was calculated from cycle threshold $(\mathrm{Cq})$ value by a $\Delta \Delta \mathrm{Cq}$ method and presented as relative to control (without MCT injection). 
A

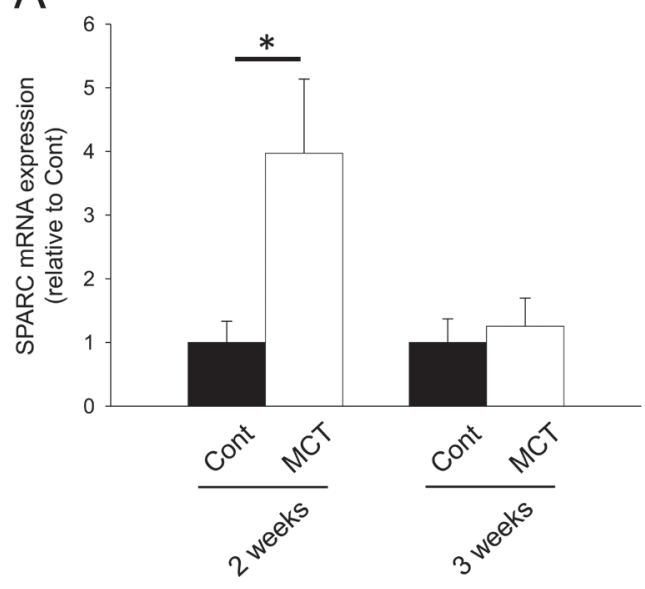

B

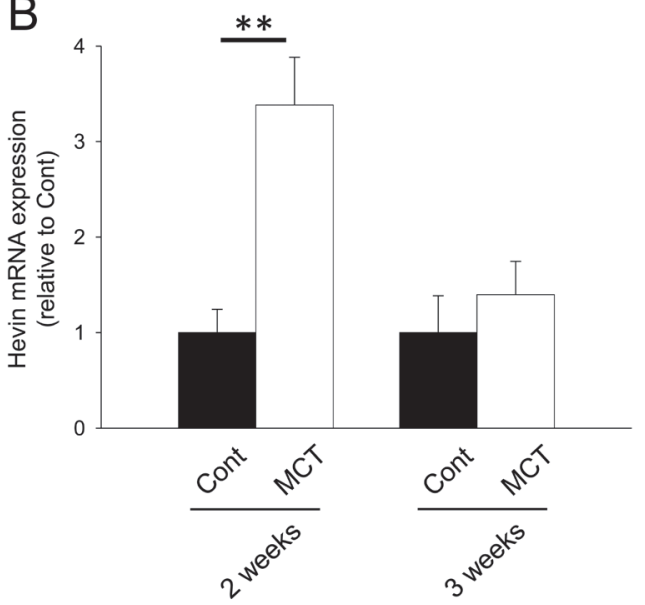

Fig. 1. mRNA expression of secreted protein acidic and rich in cysteine (SPARC) family proteins, SPARC and hevin in right ventricle (RV) of rats. Two or three weeks after monocrotaline treatment, total RNA was isolated from RV, and cDNA was synthesized. mRNA expression of SPARC family proteins was measured by real-time polymerase chain reaction (PCR). mRNA expression of SPARC (A) and Hevin (B) in RV from Cont and MCT for 2 or 3 weeks was corrected by glyceraldehyde 3-phosphate dehydrogenase (GAPDH) mRNA expression by a $\Delta \Delta \mathrm{Cq}$ method, and the normalized expression relative to Cont was shown as mean \pm standard error of the mean (S.E.M.) (2 weeks: $\mathrm{n}=5 ; 3$ weeks Cont, $\mathrm{n}=7$; and 3 weeks MCT, $\mathrm{n}=9$ ). ${ }^{*}, * * P<0.05,0.01$ vs. Cont.

\section{Statistical analysis}

The results were presented as mean \pm standard error of the mean (S.E.M.). Student's $t$-test was performed for statistical analysis. A value of $P<0.05$ was considered as statistically significant.

\section{RESULTS}

\section{$M C T$ induced pulmonary hypertension, $R V$ systolic dysfunction and $R V$ hypertrophy in rats}

We firstly confirmed that MCT induced pulmonary hypertension and RV systolic dysfunction in rats by echocardiography. Acceleration time (AcT)/ejection time (ET) ratio of pulmonary artery flow, which is an index of pulmonary arterial hypertension, was significantly decreased in MCT (2 weeks)-treatment group compared with control group (Supplemental Fig. 1A and 1B, Supplemental Table 1, $P<0.01$ ). The AcT/ET ratio was further decreased in MCT (3 weeks)-treatment group compared with control group (Supplemental Fig. 1C and 1D, Supplemental Table 1, $P<0.01$ ). TAPSE and RVESA were recorded as a parameter for right ventricular systolic function. TAPSE was significantly decreased in MCT (2 weeks)-treatment group compared with control group (Supplemental Fig. 1E and 1F, Supplemental Table 1, $P<0.05$ ), which was exaggerated in MCT (3 weeks)-treatment group (Supplemental Fig. $1 \mathrm{G}$ and 1H, Supplemental Table 1, $P<0.01$ ). RVESA was significantly increased in MCT (3 weeks)-treatment group (Supplemental Fig. 1K and 1L, Supplemental Table 1, $P<0.05$ ), but not in MCT (2 weeks)-treatment group (Supplemental Fig. 1I and 1J, Supplemental Table 1). RV weight/tail length (TL) ratio was significantly increased in MCT (2 weeks and 3 weeks)treatment groups compared with control group (Supplemental Table 2, $P<0.01$ ). On the other hand, left ventricle weight/TL ratio did not differ between MCT-treatment and control groups (Supplemental Table 2).

\section{$m R N A$ expression of matricellular proteins was increased in RV of MCT-treated rats}

We next investigated mRNA expression of matricellular proteins, SPARC family: SPARC and hevin; TSP family: TSP-1, -2 and -4; CCN family: CCN1 and 5; Tn family: TnC and N; periostin and OPN. In the RV from MCT (2 weeks)-treatment group, mRNA expression of SPARC, hevin, TSP-1, -2 and $-4, \mathrm{CCN} 1$ and 5, TnC, periostin and OPN was significantly increased (Figs. 1A, 1B, $2 \mathrm{~A}-2 \mathrm{C}, 3 \mathrm{~A}, 3 \mathrm{~B}, 4 \mathrm{~A}, 5 \mathrm{~A}$ and $5 \mathrm{~B}, P<0.05$ or $P<0.01)$. On the other hand, TnN mRNA expression was significantly decreased (Fig. 4B, $P<0.01$ ). In the RV from MCT (3 weeks)-treatment group, mRNA expression of TSP-4, CCN1 and 5 and periostin was significantly increased, while mRNA expression of TSP-1, TnC and OPN tended to increase (Figs. 2A, 2C, 3A, 3B, 4A, 5A and $5 \mathrm{~B}, P<0.05$ or $P<0.01$ ). On the other hand, there was no change in mRNA expression of SPARC, hevin, TSP-2 and TnN (Figs. 1A, 1B, 2B and 4B). Among all matricellular proteins analyzed in this study, mRNA expression of SPARC, hevin, TSP-1, -4, CCN1 and periostin was relatively higher in hypertrophied RV in MCT-treatment group (Supplemental Fig. 2).

\section{DISCUSSION}

In this study, we for the first time clarified the mRNA expression profile of matricellular proteins during the development of RV hypertrophy in MCT-induced pulmonary hypertensive rats. 
A

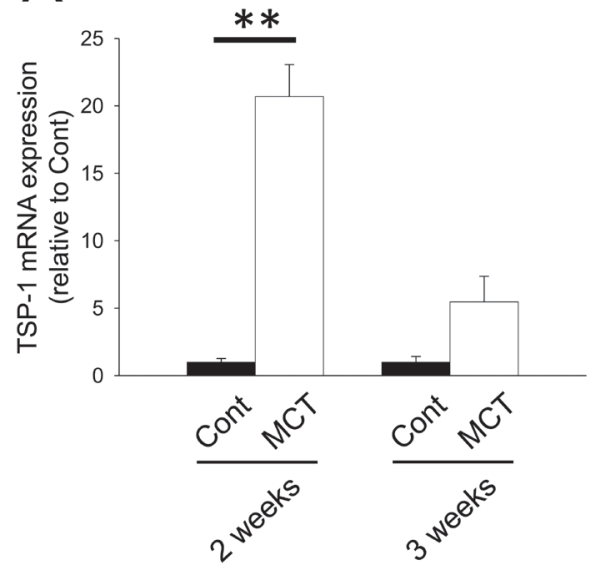

B

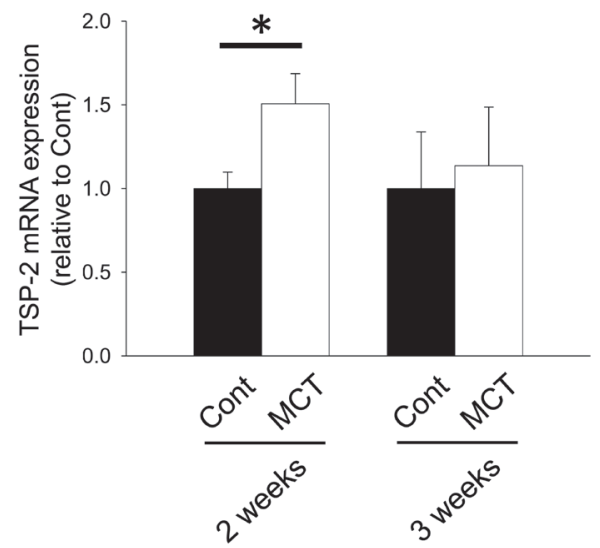

C

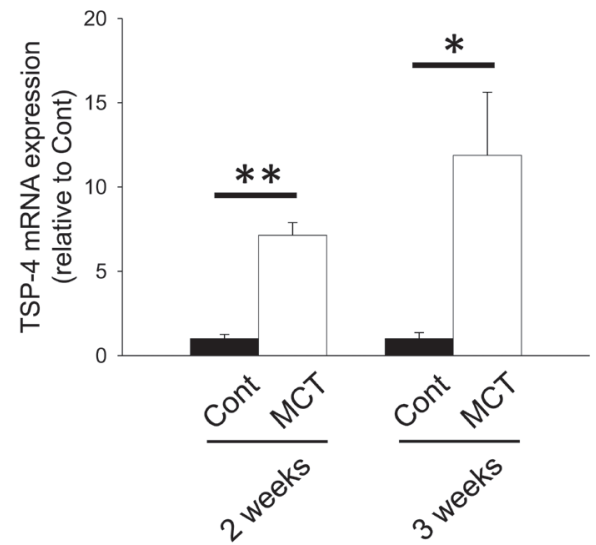

Fig. 2. mRNA expression of thrombospondins (TSP) family proteins, TSP-1, -2 and -4 , in RV of rats. Two or three weeks after monocrotaline treatment, total RNA was isolated from RV, and cDNA was synthesized. mRNA expression of TSP family proteins was measured by real-time PCR. mRNA expression of TSP-1 (A), TSP-2 (B) and TSP-4 (C) in RV from Cont and MCT for 2 or 3 weeks was corrected by GAPDH mRNA expression by a $\triangle \Delta \mathrm{Cq}$ method, and the normalized expression relative to Cont was shown as mean \pm S.E.M. ( 2 weeks: $\mathrm{n}=5$; 3 weeks Cont, $\mathrm{n}=7$; and 3 weeks MCT, $\mathrm{n}=9)$. ${ }^{*}, * * P<0.05,0.01$ vs. Cont.

A

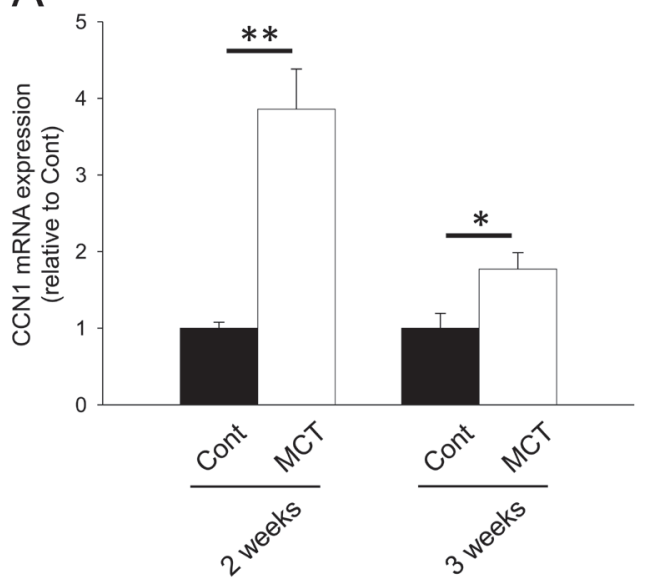

B

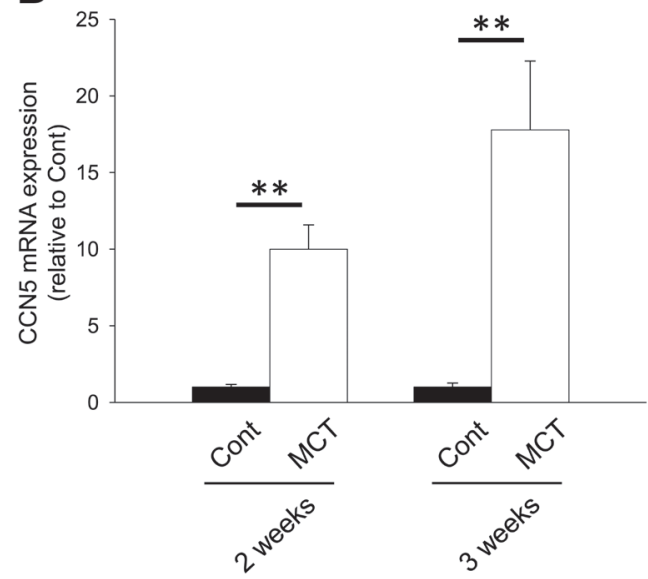

Fig. 3. mRNA expression of $\mathrm{CCN}$ family proteins, $\mathrm{CCN} 1$ and 5 in RV of rats. Two or three weeks after monocrotaline treatment, total RNA was isolated from RV, and cDNA was synthesized. mRNA expression of CCN family proteins was measured by real-time PCR. mRNA expression of CCN1 (A) and CCN5 (B) in RV from Cont and MCT for 2 or 3 weeks was corrected by GAPDH mRNA expression by a $\Delta \Delta$ Cq method, and the normalized expression relative to Cont was shown as mean \pm S.E.M. (2 weeks: $\mathrm{n}=5$; 3 weeks Cont, $\mathrm{n}=7$; and 3 weeks MCT, $\mathrm{n}=9$ ). ${ }^{*}, * * P<0.05,0.01$ vs. Cont.

RV hypertrophy is divided into an adaptive RV hypertrophy characterized by its concentric shape with retained RV function and a progressive maladaptive one characterized by ventricular dilation and severe fibrosis with RV dysfunction. MCT-induced RV hypertrophy is a model for the latter one followed by acute RV failure and death compared with the former one, such as a pulmonary artery banding model $[20,22]$. Because elucidation of bioactive matricellular proteins which play a role during the maladaptive RV hypertrophy is useful to develop a novel pharmaco-therapy, we utilized the MCT-induced RV hypertrophy model which exhibits a rapid progression of maladaptive RV hypertrophy for 2 to 3 weeks. As with the previous reports, we confirmed that MCT induced pulmonary hypertension, RV hypertrophy and dysfunction, all of which worsened over time [11]. In hypertrophied left ventricles of various cardiac disease animal models, such as angiotensin II (Ang II)-induced and transverse aortic constriction (TAC)-induced cardiac hypertrophy model mice, expression of SPARC, TnC, TSP-1, 2 and 4, CCN1 and 5 , periostin and OPN was upregulated $[1,4,9,10,15,23,25,30,32,33]$. SPARC family proteins play a role in processing of procollagen to mature collagens and in collagen fibril assembly [3, 4, 27]. Upregulated SPARC has been reported to cause diastolic dysfunction with collagen deposition and increase mortality in TAC-induced cardiac hypertrophy model mice [4]. On the other hand, SPARC gene knockdown exhibited cardiac rupture following enlargement of heart and exacerbated mortality after MI in 
A

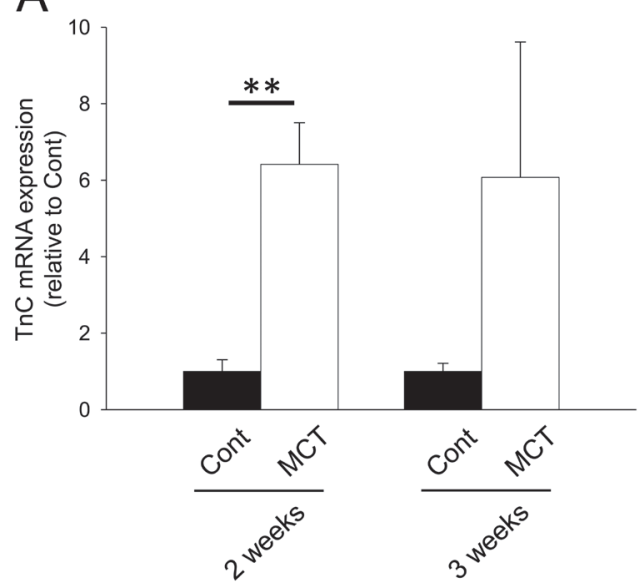

B

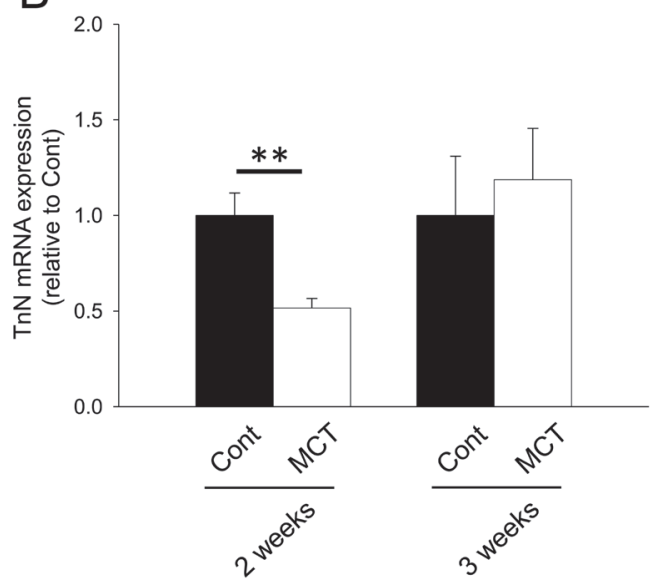

Fig. 4. mRNA expression of tenascin ( $\mathrm{Tn}$ ) family proteins, $\mathrm{TnC}$ and $\mathrm{TnN}$ in $\mathrm{RV}$ of rats. Two or three weeks after monocrotaline treatment, total RNA was isolated from RV, and cDNA was synthesized. mRNA expression of Tn family proteins was measured by real-time PCR. mRNA expression of TnC (A) and $\mathrm{TnN}$ (B) in RV from Cont and MCT for 2 or 3 weeks was corrected by GAPDH mRNA expression by a $\Delta \Delta$ Cq method, and the normalized expression relative to Cont was shown as mean \pm S.E.M. ( 2 weeks: $\mathrm{n}=5 ; 3$ weeks Cont, $\mathrm{n}=7$; and 3 weeks MCT, $\mathrm{n}=9$ ). $* * P<0.01$ vs. Cont.
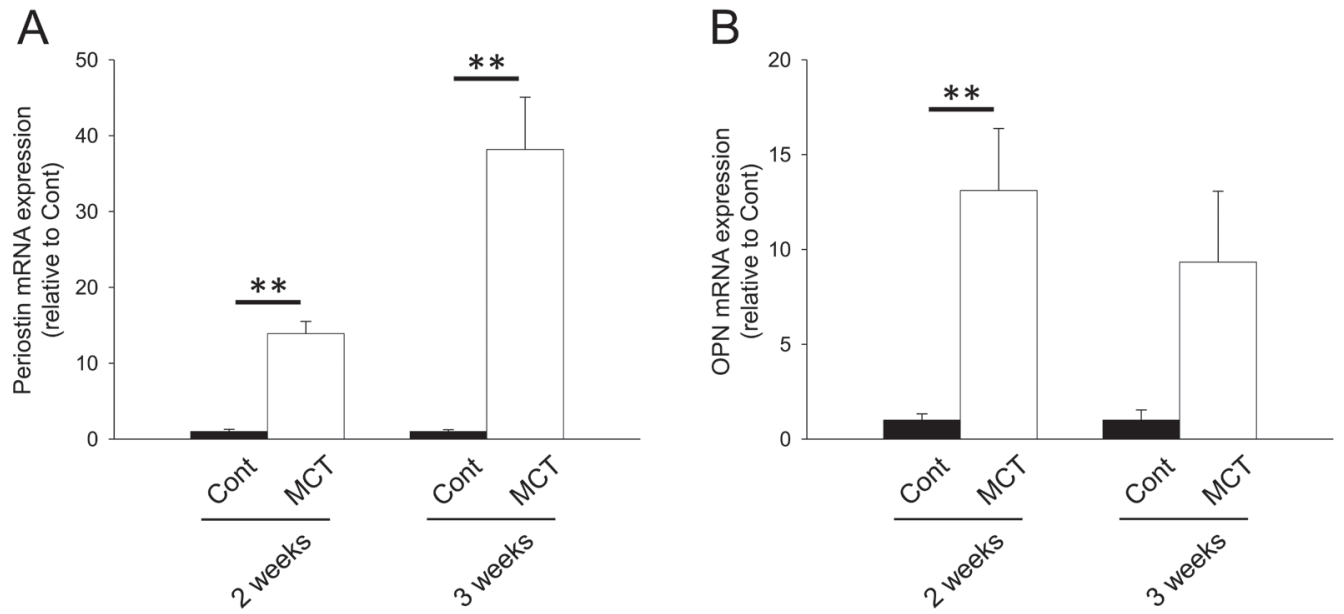

Fig. 5. mRNA expression of periostin and osteopontin $(\mathrm{OPN})$ in RV of rats. Two or three weeks after monocrotaline treatment, total RNA was isolated from RV, and cDNA was synthesized. mRNA expression of periostin and OPN was measured by real-time PCR. mRNA expression of periostin (A) and OPN (B) in RV from Cont and MCT for 2 or 3 weeks was corrected by GAPDH mRNA expression by a $\Delta \Delta \mathrm{Cq}$ method, and the normalized expression relative to Cont was shown as mean \pm S.E.M. ( 2 weeks: $\mathrm{n}=5$; 3 weeks Cont, $\mathrm{n}=7$; and 3 weeks $\mathrm{MCT}, \mathrm{n}=9) . * * P<0.01$ vs. Cont.

mice [24]. In this study, SPARC mRNA expression was increased in RV of MCT-treatment group for 2 weeks but not 3 weeks (Fig. 1A). Thus, SPARC might play a role in the early phase of MCT-induced RV hypertrophy. To the best of our knowledge, change in expression of hevin during the development of heart disease including cardiac hypertrophy has not been previously clarified. In this study, hevin mRNA expression significantly increased in RV of MCT-treatment group for 2 weeks but not 3 weeks similar to SPARC (Fig. 1B). Thus, dynamics of SPARC family proteins may be related to the early progression phase in MCT-induced RV hypertrophy. A further study is needed to clarify the exact roles of these SPARC family proteins on the pathogenesis of pressure overload-induced RV hypertrophy.

Expression of TSP-1 and -4 mRNA increased in RV from MCT (2 and 3 weeks)-treatment groups (Fig. 2A and 2C). On the other hand, TSP 2 mRNA significantly increased in RV of MCT-treatment group for 2 weeks but not 3 weeks (Fig. 2B). Gene knockdown of TSP-1 or TSP-2 was reported to deteriorate the pathology of cardiac hypertrophy induced by TAC or Ang II, respectively $[25,30]$. Therefore, TSP-1 and -2 might be involved in the development of MCT-induced RV hypertrophy. Although the role of TSP-4 in the development of cardiac hypertrophy remains to be elucidated, it may also play a role in the pathology of MCT-induced RV hypertrophy. 
Expression of CCN1 and CCN5 mRNA was consistently upregulated in MCT-induced hypertrophied RV (2 and 3 weeks) in this study (Fig. 3). In the CCN family, CCN2 (connective tissue growth factor, CTGF) is supposed to promote hypertrophic reactions and fibrosis in pressure-overloaded heart, although its effect is indirect [12]. In contrast, it is suggested that CCN5 inhibits cardiac hypertrophy and fibrosis through effects on CCN2 [33]. Thus, CCN5 might exert a cardioprotective effect on MCT-induced RV hypertrophy. Although it has been reported that CCN1 expression was upregulated in the pressure-overloaded heart, its role in the development of cardiac hypertrophy has not been clarified. Similar to that of CCN5, CCN1 is supposed to protect cardiomyocytes from oxidative stress [34]. Therefore, expression of CCN family proteins might increase as a negative feedback mechanism against MCT-induced RV hypertrophy.

In the present study, TnC mRNA expression was increased in RV from MCT (60 mg/kg, 2 and 3 weeks)-treatment groups (Fig. 4A). Hessel et al. reported that TnC expression was increased in RV from high dose ( $80 \mathrm{mg} / \mathrm{kg}, 4$ weeks) MCT-treated rats [9]. They suggested that $\mathrm{TnC}$ caused cardiomyocyte slippage followed by RV dilatation through de-adhesive activity and integrin $\beta 6$ downregulation [9]. Although RV dilatation was observed in MCT (3 weeks)-treatment group, we could not investigate the cardiomyocyte slippage. A further study is needed to clarify the relationship between TnC and RV dilatation in MCT-induced $\mathrm{RV}$ hypertrophy. Interestingly, mRNA expression of $\mathrm{TnN}$, a novel member of the tenascin family, was decreased in $\mathrm{RV}$ from MCT (2 weeks)-treatment group (Fig. 4B). The function of TnN has hardly been examined except for the modulation of neuronal migration in hippocampus, although its mechanism is still unclear [18]. It might be possible that TnN affects the migration of noncardiomyocytes, such as cardiac fibroblast, endothelial cells and macrophages, which is related to the RV remodeling process.

In the present study, mRNA expression of periostin and OPN increased in MCT-induced hypertrophied RV (Fig. 5). Periostin is thought to play a potent role in the development of cardiac hypertrophy and fibrosis, at least partly, through activating cardiac fibroblasts [19]. It was reported that deletion of the periostin gene attenuated cardiac hypertrophy and preserved systolic function in heart of TAC model mice [19]. In contrast, over expression of periostin in the heart of rats caused a cardiac dilatation [13]. Our results showed that periostin mRNA expression was notably upregulated ( $>36$-fold increase) concurrent with significant RV systolic dysfunction in MCT (3 weeks)-treatment group. Therefore, periostin might impair the systolic function of RV in MCTinduced RV hypertrophy. OPN deletion was suggested to attenuate collagen deposition and to deteriorate systolic function in the heart of Ang II-injected mice [16]. This fibrogenic property of OPN is dependent on direct effects on fibroblast activity [5]. Thus, OPN might be involved in the development of RV fibrosis.

Both mRNA expressions of SPARC and hevin were constitutively higher than the other matricellular proteins in RV (Supplemental Fig. 2). Therefore, these SPARC family proteins are important in the maintenance of homeostasis of RV. Except for TnN, mRNA expression of matricellular proteins analyzed in this study was upregulated in RV of MCT (2 weeks)-treatment group. The upregulation of mRNA expression for SPARC, hevin, TSP-1, 2 and 4, TnC, periostin and OPN in RV from MCT (2 weeks)-treatment group might be related to the development of RV fibrosis, since these matricellular proteins have been reported to possess fibrogenic activities regardless of direct or indirect effects on the ECM assembly in interstitial space [1, 3-5, 19, 25-28]. It has been reported that SPARC expression is upregulated in myofibroblasts which plays a role in the fibrosis after MI in mice [24]. TSP-1 expression is upregulated in interstitial space in TAC model mice [30]. OPN expression is also upregulated in interstitial space and interstitial cells in Ang II-induced hypertrophied left ventricles [16]. Oka et al. reported that periostin expression is upregulated in in interstitial space and interstitial cells in TAC model mice [19]. In addition, TnC expression has been reported to be upregulated in interstitial space in RV of MCT-treated rats [9]. Thus, it is suggested that interstitial cells, such as cardiac fibroblasts and myofibroblasts, are the main sources for matricellular proteins in RV of MCT-treated rats. In MCT (3 weeks)treatment group, the characteristic features of RV failure, such as RV dysfunction and dilatation, were observed (Supplemental Fig. 1G, 1H, 1K and 1L, Supplemental Table 1). Since mRNA of TSP-4 and periostin was highly expressed in RV from MCT ( 3 weeks)-treatment group, these matricellular proteins might be intimately involved in the progression of RV failure. A further study is needed to clarify the exact roles of matricellular proteins analyzed in this study during the development of RV fibrosis, dysfunction and subsequent RV failure.

The present study clarified the mRNA expression dynamics of matricellular proteins in RV of MCT-injected rats in relation to RV hypertrophy and systolic dysfunction. Our results could be helpful for finding a novel target for treatment of cardiac hypertrophy.

ACKNOWLEDGMENT. We sincerely thank Dr. Henry L. Keen for reading the manuscript and English editing.

\section{REFERENCES}

1. Belmadani, S., Bernal, J., Wei, C. C., Pallero, M. A., Dell'italia, L., Murphy-Ullrich, J. E. and Berecek, K. H. 2007. A thrombospondin-1 antagonist of transforming growth factor-beta activation blocks cardiomyopathy in rats with diabetes and elevated angiotensin II. Am. J. Pathol. 171: 777-789. [Medline] [CrossRef]

2. Berk, B. C., Fujiwara, K. and Lehoux, S. 2007. ECM remodeling in hypertensive heart disease. J. Clin. Invest. 117: 568-575. [Medline] [CrossRef]

3. Bradshaw, A. D., Puolakkainen, P., Dasgupta, J., Davidson, J. M., Wight, T. N. and Helene Sage, E. 2003. SPARC-null mice display abnormalities in the dermis characterized by decreased collagen fibril diameter and reduced tensile strength. J. Invest. Dermatol. 120: 949-955. [Medline] [CrossRef]

4. Bradshaw, A. D., Baicu, C. F., Rentz, T. J., Van Laer, A. O., Boggs, J., Lacy, J. M. and Zile, M. R. 2009. Pressure overload-induced alterations in fibrillar collagen content and myocardial diastolic function: role of secreted protein acidic and rich in cysteine (SPARC) in post-synthetic procollagen processing. Circulation 119: 269-280. [Medline] [CrossRef]

5. Collins, A. R., Schnee, J., Wang, W., Kim, S., Fishbein, M. C., Bruemmer, D., Law, R. E., Nicholas, S., Ross, R. S. and Hsueh, W. A. 2004. 
Osteopontin modulates angiotensin II-induced fibrosis in the intact murine heart. J. Am. Coll. Cardiol. 43: 1698-1705. [Medline] [CrossRef]

6. Frangogiannis, N. G. 2012. Matricellular proteins in cardiac adaptation and disease. Physiol. Rev. 92: 635-688. [Medline] [CrossRef]

7. Galiè, N., Humbert, M., Vachiery, J. L., Gibbs, S., Lang, I., Torbicki, A., Simonneau, G., Peacock, A., Vonk Noordegraaf, A., Beghetti, M., Ghofrani, A., Gomez Sanchez, M. A., Hansmann, G., Klepetko, W., Lancellotti, P., Matucci, M., McDonagh, T., Pierard, L. A., Trindade, P. T., Zompatori, M., Hoeper, M., Aboyans, V., Vaz Carneiro, A., Achenbach, S., Agewall, S., Allanore, Y., Asteggiano, R., Paolo Badano, L., Albert Barberà, J., Bouvaist, H., Bueno, H., Byrne, R. A., Carerj, S., Castro, G., Erol, Ç., Falk, V., Funck-Brentano, C., Gorenflo, M., Granton, J., Iung, B., Kiely, D. G., Kirchhof, P., Kjellstrom, B., Landmesser, U., Lekakis, J., Lionis, C., Lip, G. Y., Orfanos, S. E., Park, M. H., Piepoli, M. F., Ponikowski, P., Revel, M. P., Rigau, D., Rosenkranz, S., Völler, H. and Luis Zamorano, J. 2016. 2015 ESC/ERS Guidelines for the diagnosis and treatment of pulmonary hypertension: The Joint Task Force for the Diagnosis and Treatment of Pulmonary Hypertension of the European Society of Cardiology (ESC) and the European Respiratory Society (ERS): Endorsed by: Association for European Paediatric and Congenital Cardiology (AEPC), International Society for Heart and Lung Transplantation (ISHLT). Eur. Heart J. 37: 67-119. [Medline] [CrossRef]

8. Gosavi, S., Channa, R. and Mukherjee, D. 2015. Systemic Hypertension in Patients with Aortic Stenosis: Clinical Implications and Principles of Pharmacological Therapy. Cardiovasc. Hematol. Agents Med. Chem. 13: 50-53. [Medline] [CrossRef]

9. Hessel, M., Steendijk, P., den Adel, B., Schutte, C. and van der Laarse, A. 2009. Pressure overload-induced right ventricular failure is associated with re-expression of myocardial tenascin-C and elevated plasma tenascin-C levels. Cell. Physiol. Biochem. 24: 201-210. [Medline] [CrossRef]

10. Hilfiker-Kleiner, D., Kaminski, K., Kaminska, A., Fuchs, M., Klein, G., Podewski, E., Grote, K., Kiian, I., Wollert, K. C., Hilfiker, A. and Drexler, H. 2004. Regulation of proangiogenic factor CCN1 in cardiac muscle: impact of ischemia, pressure overload, and neurohumoral activation. Circulation 109: 2227-2233. [Medline] [CrossRef]

11. Imoto, K., Kumatani, S., Okada, M. and Yamawaki, H. 2016. Endostatin is protective against monocrotaline-induced right heart disease through the inhibition of T-type $\mathrm{Ca}(2+)$ channel. Pflugers Arch. 468: 1259-1270. [Medline] [CrossRef]

12. Iwamoto, M., Hirohata, S., Ogawa, H., Ohtsuki, T., Shinohata, R., Miyoshi, T., Hatipoglu, F. O., Kusachi, S., Yamamoto, K. and Ninomiya, Y. 2010. Connective tissue growth factor induction in a pressure-overloaded heart ameliorated by the angiotensin II type 1 receptor blocker olmesartan. Hypertens. Res. 33: 1305-1311. [Medline] [CrossRef]

13. Katsuragi, N., Morishita, R., Nakamura, N., Ochiai, T., Taniyama, Y., Hasegawa, Y., Kawashima, K., Kaneda, Y., Ogihara, T. and Sugimura, K. 2004. Periostin as a novel factor responsible for ventricular dilation. Circulation 110: 1806-1813. [Medline] [CrossRef]

14. Kögler, H., Hartmann, O., Leineweber, K., Nguyen van, P., Schott, P., Brodde, O. E. and Hasenfuss, G. 2003. Mechanical load-dependent regulation of gene expression in monocrotaline-induced right ventricular hypertrophy in the rat. Circ. Res. 93: 230-237. [Medline] [CrossRef]

15. Liu, W., Zi, M., Tsui, H., Chowdhury, S. K., Zeef, L., Meng, Q. J., Travis, M., Prehar, S., Berry, A., Hanley, N. A., Neyses, L., Xiao, R. P., Oceandy, D., Ke, Y., Solaro, R. J., Cartwright, E. J., Lei, M. and Wang, X. 2013. A novel immunomodulator, FTY-720 reverses existing cardiac hypertrophy and fibrosis from pressure overload by targeting NFAT (nuclear factor of activated T-cells) signaling and periostin. Circ Heart Fail 6: 833-844. [Medline] [CrossRef]

16. Matsui, Y., Jia, N., Okamoto, H., Kon, S., Onozuka, H., Akino, M., Liu, L., Morimoto, J., Rittling, S. R., Denhardt, D., Kitabatake, A. and Uede, T. 2004. Role of osteopontin in cardiac fibrosis and remodeling in angiotensin II-induced cardiac hypertrophy. Hypertension 43: 1195-1201. [Medline] [CrossRef]

17. Nagata, K. and Hattori, T. 2011. Cardioprotective mechanisms of lifestyle modifications and pharmacotherapies on cardiac remodeling and dysfunction in hypertensive heart disease: an overview. Nagoya J. Med. Sci. 73: 91-105. [Medline]

18. Neidhardt, J., Fehr, S., Kutsche, M., Löhler, J. and Schachner, M. 2003. Tenascin-N: characterization of a novel member of the tenascin family that mediates neurite repulsion from hippocampal explants. Mol. Cell. Neurosci. 23: 193-209. [Medline] [CrossRef]

19. Oka, T., Xu, J., Kaiser, R. A., Melendez, J., Hambleton, M., Sargent, M. A., Lorts, A., Brunskill, E. W., Dorn, G. W. 2nd., Conway, S. J., Aronow, B. J., Robbins, J. and Molkentin, J. D. 2007. Genetic manipulation of periostin expression reveals a role in cardiac hypertrophy and ventricular remodeling. Circ. Res. 101: 313-321. [Medline] [CrossRef]

20. Piao, L., Fang, Y. H., Parikh, K., Ryan, J. J., Toth, P. T. and Archer, S. L. 2013. Cardiac glutaminolysis: a maladaptive cancer metabolism pathway in the right ventricle in pulmonary hypertension. J. Mol. Med. 91: 1185-1197. [Medline] [CrossRef]

21. Ruilope, L. M. and Schmieder, R. E. 2008. Left ventricular hypertrophy and clinical outcomes in hypertensive patients. Am. J. Hypertens. 21: 500-508. [Medline] [CrossRef]

22. Ryan, J. J. and Archer, S. L. 2014. The right ventricle in pulmonary arterial hypertension: disorders of metabolism, angiogenesis and adrenergic signaling in right ventricular failure. Circ. Res. 115: 176-188. [Medline] [CrossRef]

23. Rysä, J., Leskinen, H., Ilves, M. and Ruskoaho, H. 2005. Distinct upregulation of extracellular matrix genes in transition from hypertrophy to hypertensive heart failure. Hypertension 45: 927-933. [Medline] [CrossRef]

24. Schellings, M. W., Vanhoutte, D., Swinnen, M., Cleutjens, J. P., Debets, J., van Leeuwen, R. E., d'Hooge, J., Van de Werf, F., Carmeliet, P., Pinto, Y. M., Sage, E. H. and Heymans, S. 2009. Absence of SPARC results in increased cardiac rupture and dysfunction after acute myocardial infarction. $J$. Exp. Med. 206: 113-123. [Medline] [CrossRef]

25. Schroen, B., Heymans, S., Sharma, U., Blankesteijn, W. M., Pokharel, S., Cleutjens, J. P., Porter, J. G., Evelo, C. T., Duisters, R., van Leeuwen, R. E., Janssen, B. J., Debets, J. J., Smits, J. F., Daemen, M. J., Crijns, H. J., Bornstein, P. and Pinto, Y. M. 2004. Thrombospondin-2 is essential for myocardial matrix integrity: increased expression identifies failure-prone cardiac hypertrophy. Circ. Res. 95: 515-522. [Medline] [CrossRef]

26. Subramanian, A. and Schilling, T. F. 2014. Thrombospondin-4 controls matrix assembly during development and repair of myotendinous junctions. eLife 3: e02372. [Medline] [CrossRef]

27. Sullivan, M. M., Barker, T. H., Funk, S. E., Karchin, A., Seo, N. S., Höök, M., Sanders, J., Starcher, B., Wight, T. N., Puolakkainen, P. and Sage, E. H. 2006. Matricellular hevin regulates decorin production and collagen assembly. J. Biol. Chem. 281: 27621-27632. [Medline] [CrossRef]

28. Tamaoki, M., Imanaka-Yoshida, K., Yokoyama, K., Nishioka, T., Inada, H., Hiroe, M., Sakakura, T. and Yoshida, T. 2005. Tenascin-C regulates recruitment of myofibroblasts during tissue repair after myocardial injury. Am. J. Pathol. 167: 71-80. [Medline] [CrossRef]

29. Xia, Y., Lee, K., Li, N., Corbett, D., Mendoza, L. and Frangogiannis, N. G. 2009. Characterization of the inflammatory and fibrotic response in a mouse model of cardiac pressure overload. Histochem. Cell Biol. 131: 471-481. [Medline] [CrossRef]

30. Xia, Y., Dobaczewski, M., Gonzalez-Quesada, C., Chen, W., Biernacka, A., Li, N., Lee, D. W. and Frangogiannis, N. G. 2011. Endogenous thrombospondin 1 protects the pressure-overloaded myocardium by modulating fibroblast phenotype and matrix metabolism. Hypertension 58: 902-911. [Medline] [CrossRef]

31. Xiang, S., Zhang, N., Yang, Z., Bian, Z., Yuan, Y. and Tang, Q. 2016. Achievement of a target dose of bisoprolol may not be a preferred option for attenuating pressure overload-induced cardiac hypertrophy and fibrosis. Exp. Ther. Med. 12: 2027-2038. [Medline]

32. Xie, Z., Singh, M. and Singh, K. 2004. Osteopontin modulates myocardial hypertrophy in response to chronic pressure overload in mice. Hypertension 44: 826-831. [Medline] [CrossRef]

33. Yoon, P. O., Lee, M. A., Cha, H., Jeong, M. H., Kim, J., Jang, S. P., Choi, B. Y., Jeong, D., Yang, D. K., Hajjar, R. J. and Park, W. J. 2010. The opposing effects of CCN2 and CCN5 on the development of cardiac hypertrophy and fibrosis. J. Mol. Cell. Cardiol. 49: 294-303. [Medline] [CrossRef]

34. Yoshida, Y., Togi, K., Matsumae, H., Nakashima, Y., Kojima, Y., Yamamoto, H., Ono, K., Nakamura, T., Kita, T. and Tanaka, M. 2007. CCN1 protects cardiac myocytes from oxidative stress via beta1 integrin-Akt pathway. Biochem. Biophys. Res. Commun. 355: 611-618. [Medline] [CrossRef] 